\title{
Short Paper: Indoor Air Quality Assessments of Diverse Buildings in an Energy Conservation District from a Life Cycle Assessment Lens
}

\author{
Harold J. Rickenbacker William O. Collinge Vaclav Hasik Melissa M. Bilec \\ Department of Civil and Environmental Engineering, University of Pittsburgh \\ 153 Benedum Hall \\ Pittsburgh PA, 15261 \\ $+14126488075$
}

hjr12, woc6, vah16, mbilec@pitt.edu

\begin{abstract}
The historic reliance on fossil fuels as a primary energy source has made combating climate change one of the leading environmental challenges facing society today. Buildings account for $72 \%, 39 \%$, $38 \%$, and $14 \%$ of electricity consumption, energy use, carbon dioxide emissions, and water consumption, respectively [1-2]. Twelve cities have joined the Architecture 2030 District Challenge to aim to achieve $50 \%$ reductions in water use, energy consumption, and carbon emissions by the year 2030 [3]. Unique to the Pittsburgh's 2030 District is the inclusion of evaluating and improving indoor air quality (IAQ). Using life cycle assessment (LCA) based models and real-time pollutant monitoring, we aim to quantify the longitudinal impact energy conservation districts (ECD) have on ambient air quality and IAQ. Indoor parameters included within our research study include ozone, carbon monoxide, carbon dioxide, temperature, relative humidity, volatile organic compounds, black carbon, and particulate matter. IAQ assessments have been completed in six representative commercial buildings ranging from LEED Platinum certified to older, building stock, vintage 1900s. Preliminary results suggest significant difference in pollutant concentrations across ventilation functionality, showing a dominant effect on pollutant dilution related to newer buildings having continuous forced air, filtered and then supplied to the workspace through fans and ducts. Older buildings rely on operable windows and window air conditioners for ventilation, which provide minimum filtration and limited manual control of outdoor air intake influenced by plumes of ambient air pollution which vary temporally and spatially, attributable to industrial and traffic sources [4].
\end{abstract}

\section{CCS Concepts}

- Hardware $\sim$ Sensor applications and deployments

- Hardware Impact on the environment - Hardware

Emerging tools and methodologies $\bullet$ Hardware $\sim$ Temperature monitoring $\bullet$ Hardware $\sim$ Sensor devices and platforms

\section{Keywords}

indoor air quality (IAQ); outdoor air; life cycle assessment (LCA); energy conservation districts (ECD); particulate matter (PM); black carbon (BC); climate change, real-time air sensors

\footnotetext{
Permission to make digital or hard copies of all or part of this work for personal or classroom use is granted without fee provided that copies are not made or distributed for profit or commercial advantage and that copies bear this notice and the full citation on the first page. Copyrights for components of this work owned by others than ACM must be honored. Abstracting with credit is permitted. To copy otherwise, or republish, to post on servers or to redistribute to lists, requires prior specific permission and/or a fee. Request permissions from Permissions@acm.org.

BuildSys '16, November 16-17, 2016, Palo Alto, CA, USA

(C) 2016 ACM. ISBN 978-1-4503-4264-3/16/11 ..\$15.00

DOI: http://dx.doi.org/10.1145/2993422.2993424
}

\section{INTRODUCTION}

The U.S. building sector accounts for the largest amount of total carbon dioxide emissions annually, and close to 110,000 newly constructed commercial buildings every year [5]. Electricity consumption amounts to the largest energy source and expenditures of buildings at $72 \%$ and $65 \%$ per annum, respectively [6]. Furthermore, the fuel combustion processes needed to generate energy and electricity consequently impact environmental degradation, heavily influencing greenhouse gas (GHG) and particulate matter (PM) emissions. Nationally $13.4 \%$ of PM2.5 emissions are produced during fuel combustion; whereas, in Allegheny County, PA (Pittsburgh), 41.4\% of PM2.5 is from fuel combustion [7]. The reason from the difference is due to a number of factors including legacy power plants. Across building types, office and retail workspace are some of the most energy intensive [6]; hence, working with these building types in the Pittsburgh 2030 District can serve as ideal testbeds to address tangible energy reduction measures and in turn have longitudinal impacts on both ambient and indoor air quality.

As the Pittsburgh 2030 District works to decrease community-wide energy use and greenhouse gas emissions (GHG), we hypothesize these reductions should in turn lead to improvements in ambient air quality and further elucidate improvements (or declines) in indoor air quality. This paper focuses on our pilot study and preliminary results. We have collaborated with our living laboratory partner the Pittsburgh 2030 District, which comprises 85 owners/partners, 438 properties, and 68.2 million square feet of space (Figure 1) - all committed to working towards energy conservation district (ECD)

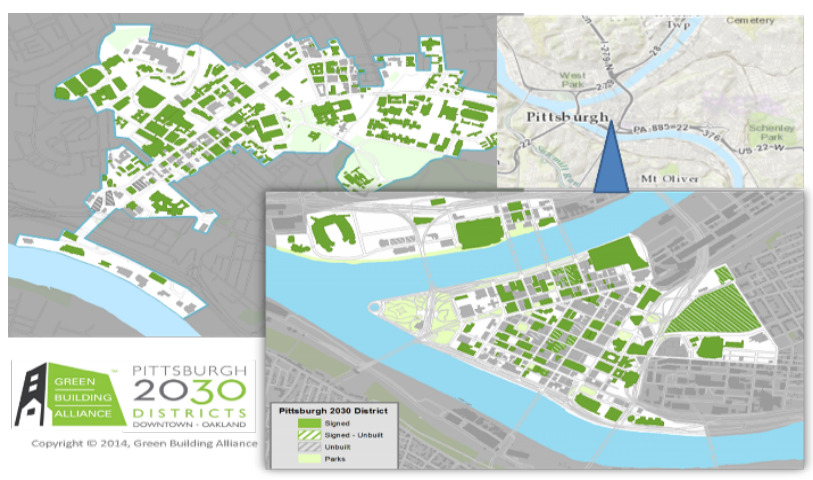

Figure 1: The Pittsburgh 2030 District's location, boundaries and committed properties. Energy baselines were set in 2013; as of June 2016 the Pittsburgh 2030

Districts report a $12.5 \%, 10.3 \%$, and $24.2 \%$ reduction in energy use, water consumption, and carbon emissions, respectively $[8]$. 
goals. While the compelling, motivating and necessary goal of 2030 communities is to achieve a dramatic reduction in energy usage and associated GHG emissions in the building sector, we believe that this challenge needs to be undertaken with the consideration of improving the health of the places where we spend $90 \%$ of our time. Our long-term research approach involves a unique mix of strategies including: (1) Convening district stakeholders and ascertaining existing indoor air quality data; (2) Developing and implementing a meaningful and scalable indoor air quality protocol for a large and diverse building data set; (3) Collecting, storing, and benchmarking the indoor air quality data with respect to building parameters and outdoor air conditions; and (4) Incorporating existing and proposed energy and emission reduction strategies into a holistic life cycle assessment model that incorporates field-verified indoor air quality impacts. Significantly, a large scale, regionally specific life cycle assessment (LCA) of whole buildings including both indoor and outdoor impacts, has yet to be undertaken in the United States.

\section{APPROACH AND METHODS}

With assistance from the Green Building Alliance (GBA), the organizers of the Pittsburgh 2030 District, we solicited volunteer buildings/partners to participate in our first phase pilot. Performance successes are reported monthly to a mixed audience of building owners, employees, and decision-makers, proving the GBA as a pivotal role-player and planning nexus for the 2030 Districts. This approach allows for crosspollination of efficiency efforts and the formulation of building case studies that outline tangible energy reduction recommendations for 2030 partners to adopt. Several indoor air quality studies have linked substantial health and productivity gains to improved indoor environmental quality $[9,10,11]$. Employee salaries and healthcare cost dominate expenditures in the commercial sector, therefore even minor improvements in health and productivity can drive tremendous financial gains for companies as well [9].

\subsection{Air Sampling Protocol}

The Environmental Protection Agency (EPA) conducted the BASE study in 2006 where IAQ assessments were conducted in 100 randomly selected public and commercial offices over a three-day sampling period [12]. Using the protocol from the BASE study, we developed our testing protocol and measurement parameters specific to the work in the 2030 District with more focus on spatial and temporal detail of measurements and fewer individual chemicals. The IAQ monitoring protocol includes (1) an initial building and site visit, (2) selection of specific study areas and monitoring locations, (3) 72-hour field monitoring, and (4) data synthesize and reporting. The predefined test locations are measured both in the morning, as well as in the afternoon and overnight. On each subsequent sampling day, testing locations are randomized to minimize any nuisance factors that may influence testing variables. Indoor air quality and ambient pollutant concentrations are compared to acceptable levels published in ANSI/ASHRAE 62.2013 Ventilation for Acceptable Indoor Air Quality, ANSI/ASHRAE 55.2013 Thermal Environmental Conditions for Human Occupancy, and the EPA's National Ambient Air Quality Standards (NAAQS) [13, 14, 15]. A followup meeting is conducted with key site personnel to disseminate the results and outline tangible recommendations moving forward.

\subsection{Air Sampling Equipment and Parameters Measured}

Our research team deployed the Graywolf 3016 Handheld airborne particle counter which uses light scattering to measure particulate matter in six size channels, $\mathrm{PM}_{0.5}, \mathrm{PM}_{1.0}, \mathrm{PM}_{2.5}, \mathrm{PM}_{5.0}, \mathrm{PM}_{10}$, and $>$ $\mathrm{PM}_{10}$, and the Graywolf AdvancedSense Probe to capture real time concentrations of total volatile organic compounds (TVOC), carbon dioxide $\left(\mathrm{CO}_{2}\right)$, carbon monoxide $(\mathrm{CO})$, relative humidity $(\mathrm{RH})$, ozone $\left(\mathrm{O}_{3}\right)$, temperature, and formaldehyde (HCHO). Graywolf equipment undergoes annual National Institute of Standards and Technology (NIST) calibration to ensure data accuracy and validity. Black carbon (BC) samples are collected using AethLab's Micro-Aethalometer. Dylos particle counters are inexpensive and light weight, used as roamers to expand our coverage area to intake vents, streetscape, and simultaneous monitoring of multiple floors at once.

\section{RESULTS and DISCUSSION}

The results sections first examine particulate matter concentrations across the six IAQ Pilot buildings, all with unique ventilation 'functionality.' Mechanically ventilated buildings reduce indoor concentrations of particulate matter through the implementation of filtration mechanisms in the supply and return ducts of HVAC systems. Conversely, older buildings built in the 1900s have minimum mechanical ventilation and rely on leaky envelopes to deliver outdoor air circulation. Centralized HVAC system prevalence lowers the indoor penetration of outdoor PM through filtration, when compared to utilizing opened windows as cooling mechanisms [16]. Operable windows provide natural, but unfiltered, ventilation limiting the mitigation of pollutant infiltration influenced by the outdoor air environment. Particulates were measured as total number per cubic foot of air. The particles were classified as $\mathrm{PM}_{2.5}$ (0.3-2.5 microns) and $\mathrm{PM}_{10}$ (2.5-10 microns). $\mathrm{PM}_{2.5}$ is considered highly respirable particles that can easily infiltrate the upper respiratory track and lead to chronic exposure health impairments [17]. $\mathrm{PM}_{10}$ generally does not by-pass the mucous membranes of the nose, throat, and eyes [17].

Secondly, the results explore May 2016 concentrations of $\mathrm{BC}, \mathrm{CO}_{2}$, and $\mathrm{PM}_{2.5}$ in one of the older pilot buildings. The workspaces utilize diverse climate control equipment, and serve a range of activities. The indoor spaces have been renovated several times since the construction of the building in 1917; however, the renovations have never been done as a uniform upgrade of the entire building, each space has been transformed individually by floors or even parts of a floor.

Figure 2 shows averages across the three day sampling period for $\mathrm{PM}_{2.5}$ and $\mathrm{PM}_{10} \mathrm{ug} / \mathrm{m}^{3}$ of the six pilot buildings characterized as: Minimum mechanical ventilation/MMV (window $\mathrm{A} / \mathrm{C}$ units and operable windows), Both ventilation/BV (window $\mathrm{A} / \mathrm{C}$ Units + mechanical systems), Mechanical ventilation/MV (centralized HVAC)]. The NAAQS and ANSI/ASHRAE standards set acceptable exposure limits of $\mathrm{PM}_{2.5}$ at $35 \mathrm{ug} / \mathrm{m}^{3}$ (24 hours), and $\mathrm{PM}_{10}$ at $150 \mathrm{ug} / \mathrm{m}^{3}$ (24 hours) $[13,15]$. As expected the results suggest difference in concentrations across ventilation functionality, showing a dominant effect on pollutant dilution related to newer buildings having continuous forced air, filtered and then supplied to the workspace through fans and ducts.

Figure 3 illustrates preliminary data for one of the representative 1900 buildings in the 2030 Districts showing a relationship between $\mathrm{PM}_{2.5}, \mathrm{BC}$ and occupant interactions $\left(\mathrm{CO}_{2}\right)$. Human respiration is a dominant source of $\mathrm{CO}_{2}$ indoors, hence using elevated levels of $\mathrm{CO}_{2}$ as a marker compound for events of resuspension influenced by anthropogenic activities.

Preliminary data and observations documented during Steps (2) and (3) of the air sampling protocol suggest $\mathrm{PM}_{2.5}$ and Black Carbon (BC) are affected predominantly by factors relating to building 


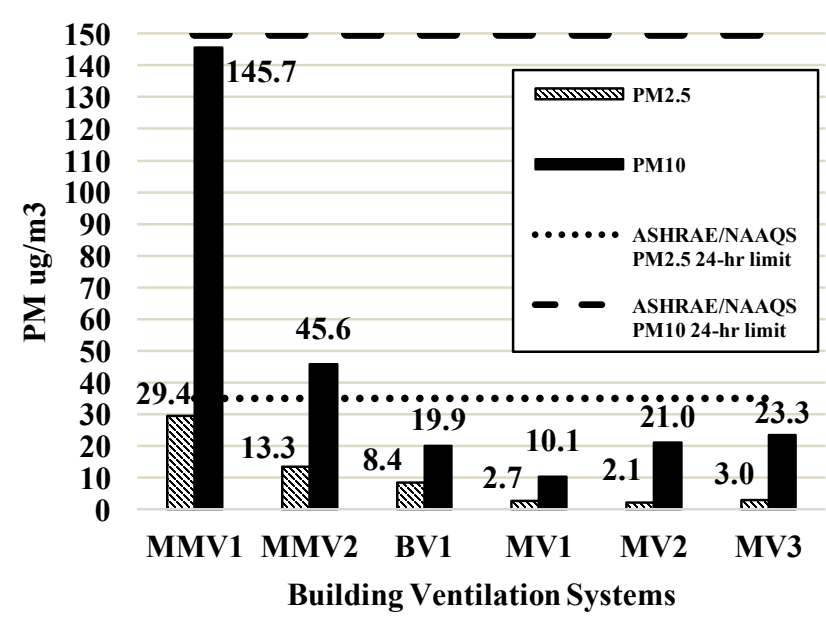

Figure 2: Average $\mathrm{PM}_{2.5}$ and $\mathrm{PM}_{10}$ from six pilot buildings. The NAAQS and ANSI/ASHRAE standards set acceptable exposure limits of $P M_{2.5}$ at $35 \mathrm{ug} / \mathrm{m}^{3}$ (24 hours), and $P M_{10}$ at $150 \mathrm{ug} / \mathrm{m}^{3}(24$ hours) $[13,15]$ [Minimum mechanical ventilation/MMV (window $\mathrm{A} / \mathrm{C}$ units and operable windows), Both ventilation/BV (window A/C Units + mechanical systems), Mechanical ventilation/MV (centralized HVAC)].

materials and infrastructure, routine cleaning and maintenance practices, building envelope, flooring type, the presence or lack of filtration, traffic density, and increased anthropogenic activities indoors. Common indoor sources of $\mathrm{PM}_{2.5}$ and $\mathrm{BC}$ include printers and copiers [18], radiant space heaters [19], aging carpet [20], and practices such as cooking, smoking, and cleaning activities [19, 21]. Mobile sources account for $52 \%$ of BC emissions in the U.S. [22]. Interstate highways I-376, I-579, and I-279 that surround the energy conservation districts (ECD) in Pittsburgh, contribute to ambient air pollution, and largely impact $\mathrm{PM}_{2.5}$ and $\mathrm{BC}$ concentrations during different portions of the day reflective of dense bus traffic and morning and evening rush hours.

Aiming to reduce the regional carbon footprint, 2030 partners have made significant changes in building systems and everyday operations to meet the explicit goals of the initiative. Based on air quality field test and real-time monitoring data, recommendations are made to specific building owners and maintenance staff on a case-by-case basis detailing ways to reduce energy consumption and minimize air toxicant exposure. A list of tangible recommendation adopted by 2030 partners include: upgrading existing filters to a higher MERV rating and replacing filters on a seasonal basis for maximum efficiency; investing in HEPA vacuum cleaners to limit resuspension of fine particles; purchasing Environmentally Preferable Products (EPP) for cleaning to limit TVOC exposure; spotlight cleaning of mechanical equipment as particles can be deposited and overtime induce bacteria and fungi growth in HVAC ductwork, window $\mathrm{A} / \mathrm{C}$ units, and radiant heaters; adoption of day cleaning strategies to limit overnight operating hours; robust HVAC management, shutting down systems at $6 \mathrm{pm}$ and starting again at 3 am to reduce energy cost; and active replacement of existing office equipment with all-in-one or ink jet printers and copiers that off-gas less ozone, VOCs, and particulates. New initiatives and retrofit programs, have also been implemented city-wide such as; the Green Construction Certification Program mandating new construction projects to add pollutant suppressors to all heavy equipment; the Green Garage Initiative upgrading all lighting in parking garages to LED and motion sensors; administration of the "Make My Trip Count" commuters survey to further quantify diesel emissions with active participation from over 20,000 Pittsburghers; and accessibility and installation of green roofs for noise abatement, aesthetic harmony, sequestration of gaseous pollutants and urban heat island mitigation [5].

\section{CONCLUSION}

Twenty-four hour integrated predicted PM2.5 exposure surface maps produced by Tunno et al. [23] compared the spatial variability in pollutant dispersion in the Pittsburgh region showing building occupants in the urban center of the city are at elevated risk to poor indoor air quality exposure. The results suggest factors such as proximity to Toxic Release Inventory (TRI) sites, traffic related air pollution, and topography significantly impact intra-urban air pollution concentrations across seasons. Downtown Pittsburgh also sits along the Monongahela and Allegheny River Valley enabling pollution to hover impacting both indoor and ambient air, due to meteorological patterns and atmospheric inversion events [23]. Older building stock in Downtown Pittsburgh relies on radiant heaters to provide space heating during winter months, resulting in potentially inadequate air exchange rates and elevated levels of $\mathrm{CO}_{2}$ and Particulate Matter produced internally with no active mode of filtration.

Five of 11 states with the highest year-round particle pollution are participating in the Architecture 2030 Challenge - (1) California, (2) Pennsylvania, (3) Ohio, (4) Texas, (5) Michigan; their participation proves pivotal in addressing energy consumption and air pollution on a national scale. Furthermore, Pittsburgh is ranked 8th out of 171 metropolitan areas for annual particle pollution [24]. Our research advances fundamental science as well as informs best practices within the broader scientific and professional communities. Development of concrete recommendations that

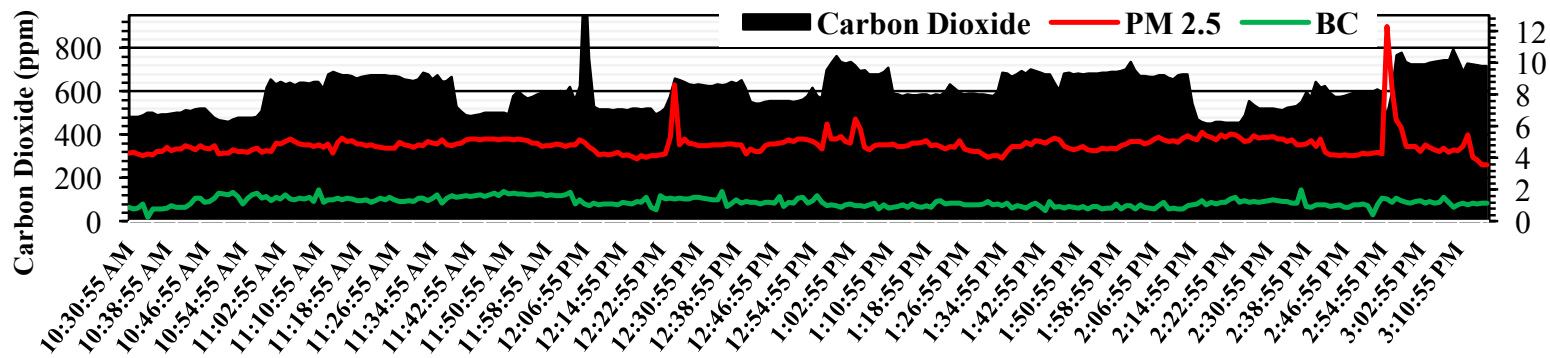

\section{Sampling Time May 2016 (hh:mm:ss)}

Figure 3: IAQ Concentrations for 1917 Building (Minimum mechanical ventilation/MMV). Clerical work, the use of printers/copiers, and occupant-traffic flow increases in the late morning and early afternoon, when compared to the building being vacant overnight and less occupied in the early mornings upon open and operations. As anthropogenic activities increase indoors the coagulation and disposition of particles also increase as a function of time. 
other districts and individual buildings can implement in the future is a primary research goal. We envision that the protocol will have several elements - first, will be the creation of a database reconciling, cost of implementation, emerging IAQ technology, and desirable results. Second, we will determine concise and practical recommendations on balancing IAQ and energy use for the use of property owners and maintenance management municipalities. The operation and use phase of buildings represent the greatest environmental and human health impacts (70-90\%) [25], and moreover, our overall mission is to scientifically quantify and communicate the explicit message that energy improvements are best made in harmony with indoor air quality considerations.

\section{FUTURE WORK}

Development of the IAQ baseline will be ongoing throughout monitoring activities, which will last over several years. Future work includes two major aspects. We will use the collected IAQ baseline data to evaluate proposed energy and emissions reduction measures through development of a dynamic life cycle assessment (DLCA) model [26]. HVAC system modifications that change ventilation or filtration rates can have an impact on IAQ, whereas almost any energy use reduction can have an indirect impact by reducing emissions from the upstream processes used in power generation inclusive of - but broader than - the energy conservation district (ECD) itself. Internal health and productivity impacts from external sources will be somewhat lowered, but internal impacts from internal sources have to be further quantified. These types of tradeoffs or synergies have been identified conceptually, but the development of a indoor environmental quality and dynamic life cycle assessment framework (IEQ+DLCA) has significant promise to improve the quantification and regional variability in these measures. Second, multiple linear regression models and other simple data reduction techniques will be employed within hierarchical categories of IAQ typologies, to examine the statistical significance and predictability of effects. Analysis of Variance (ANOVA) statistical models will be used to define relationships between indoor air quality and built environment parameters, exploring relationships across sampling locations, building floors, and building type.

\section{ACKNOWLEDGMENTS}

We would like to acknowledge the University of Pittsburgh's Mascaro Center for Sustainable Innovation for their support. This material is based upon work supported by the National Science Foundation under EFRI-SEED (161996). Any opinions, findings, and conclusions or recommendations expressed in this material are those of the author(s) and do not necessarily reflect the views of the National Science Foundation.

\section{REFERENCES}

[1] US Department of Energy (USDOE), "Energy Sources," 2016. http://energy.gov/science-innovation/energy-sources

[2] US Geological Survey (USGS) "Water Use in the United States," 2016. http://water.usgs.gov/watuse/

[3] Architecture 2030, "The 2030 Challenge," 2015. http://architecture2030.org/2030_challenges/2030-challenge/

[4] Clougherty, J.E., Houseman, E.A., Levy, J.I., "Source apportionment of indoor residential fine particulate matter using land use regression and constrained factor analysis." 2011, Indoor Air 21 (1), 53-66.

[5] Energy Information Administration (EIA), "Annual Energy Outlook 2008, Table A5, "new additions" through the year 2010," http://www.eia.gov/

[6] USDOE, "Energy efficiency trends in residential and commercial buildings," 2008. Washington, D.C.: U.S. Dept. of Energy, Energy Efficiency and Renewable Energy.

[7] USEPA, "National Emissions Inventory (NEI) Data," 2011. https://www.epa.gov/air-emissions-inventories/2011-nationalemissions-inventory-nei-data

[8] Green Building Alliance, "Pittsburgh 2030 District," 2015. https://www.go-gba.org/initiatives/pittsburgh-2030-district/

[9] Fisk, W., "Estimates of potential nationwide productivity and health benefits from better indoor environments: An update," 2000. Indoor Air Quality Handbook.

[10] Heschong, L., Wright, R. L., and Okura, S., "Daylighting Impacts on Human Performance in School," 2002. Journal of the Illuminating Engineering Society, 31:2, pp. 21-25.

[11] Tham, KW, HC Willem, SC Sekhar, DP Wyon, P Wargocki, PO Fanger, "Temperature and ventilation effects on the work performance of office workers (study of a call center in the tropics)," 2003. In Proceedings of Healthy Buildings 2003, December 7-11, 2003, Singapore

[12] USEPA, "A Standardized EPA Protocol for Characterizing indoor Air Quality in Large Office Buildings," 2003. Office of Research and Development and Office of Air and Radiation, U.S. EPA Washington, DC.

[13] ASHRAE, “ANSI/ASHRAE Standard 62.1-2013, Ventilation for Acceptable Indoor Air Quality,” 2013. American Society of Heating, Refrigeration and Air Conditioning Engineers (ASHRAE): Atlanta, GA.

[14] ASHRAE, "ANSI/ASHRAE Standard 55.1-2013, Thermal Environmental Conditions for Human Occupancy," 2013. American Society of Heating, Refrigeration and Air Conditioning Engineers (ASHRAE): Atlanta, GA.

[15] USEPA, "National Ambient Air Quality Standards," 2016. https://www.epa.gov/criteria-air-pollutants/naaqs-table

[16] Bell, M. L., Ebisu, K., Peng, R. D., \& Dominici, F., “Adverse Health Effects of Particulate Air Pollution: Modification by Air Conditioning," 2009. Epidemiology (Cambridge, Mass.), 20(5), 682-686. http://doi.org/10.1097/EDE.0b013e3181aba749

[17] USEPA, "Report to Congress on indoor air quality: Volume 2," 1989. EPA/400/1-89/001C. Washington, DC

[18] S.C. Lee, S. Lam, H. Kin Fai, "Characterization of VOCs, ozone, and PM10 emissions from office equipment in an environmental chamber, " 2001. Build. Environ. 36, 837e842, http://dx.doi.org/10.1016/S03601323(01)00009-9

[19] Semple S, Garden C, Coggins M, et al. "Contribution of solid fuel, gas combustion or tobacco smoke to indoor air pollutant concentrations in Irish and Scottish homes,” 2012. Indoor air.;22(3):212-223. doi:10.1111/j.1600-0668.2011.00755.x.

[20] Thornburg, Jonathan. "Resuspension and Tracking of Particulate Matter From Carpet Due to Human Activity Final Report," 2007. RTI International

[21] Abt E, Suh HH, Allen G, Koutrakis P., "Characterization of indoor particle sources: A study conducted in the metropolitan Boston area. Environmental Health Perspectives," 2000.108(1):35-44.

[22] USEPA, "Report to Congress on Black Carbon," 2003. http://www3.epa.gov/blackcarbon/2012report/Chapter4.pdf

[23] Tunno BJ, Michanowicz DR, Shmool JLC, et al. "Spatial variation in inversion-focused vs 24-h integrated samples of PM2.5 and black carbon across Pittsburgh, PA," 2016. Journal of Exposure Science \& Environmental Epidemiology. 26(4):365-376. doi:10.1038/jes.2015.14.

[24] American Lung Association, "State of the Air: Most Polluted Cities," 2015. http://www.stateoftheair.org/2015/city-rankings/most-pollutedcities.html

[25] Ortiz, O.; Castells, F.; Sonnemann, G., "Sustainability in the construction industry: A review of recent developments based on LCA," 2009. Construction and Building Materials, 23 (1), 28-39.

[26] Collinge, W.O., Landis, A.E., Jones, A.K., Schaefer, L.A., Bilec, M.M., "Productivity metrics in dynamic LCA for whole buildings: using a post-occupancy evaluation to evaluate energy and indoor environmental quality tradeoffs, " 2014. Building and the Environment. 82, December 2014, 339-34 